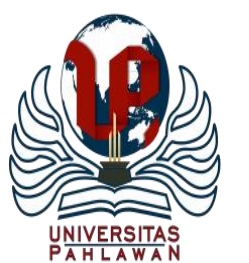

Jurnal Abdidas Volume 2 Nomor 4 Tahun 2021 Halaman 774-782

JURNAL ABDIDAS

http://abdidas.org/index.php/abdidas

\title{
Bimbingan Teknis Pengawasan Bagi Komite Audit Koperasi Credit Union Hati Amboina
}

\author{
Ignatius Samson Refo ${ }^{1}$, Maria J.F Esomar ${ }^{2 \varpi,}$ Adonia Anita Batkunde ${ }^{3}$ \\ Sosiologi, STPAK Ambon, Indonesia ${ }^{1}$ \\ Manajemen, Universitas Pattimura, Indonesia ${ }^{2}$ \\ Akuntansi, Universitas Pattimura, Indonesia ${ }^{3}$ \\ E-mail: ignasiusrefo@gmail.com ${ }^{1}$ dyahesomar@gmail.com ${ }^{2}$ mejagayofa02@gmail.com ${ }^{3}$
}

\begin{abstract}
Abstrak
Pelaksanaan pengawasan atau audit sangat diperlukan untuk menjamin tata kelola koperasi yang sehat. Komite Audit harus memahami auditing dan prosedur audit agar aktivitas audit internal dapat berjalan baik. Tujuan dari kegiatan ini adalah untuk memberikan bimbingan secara teknis kepada komite audit koperasi credit union Hati Amboin untuk memaksimalkan fungsi pengawasan pada kantor pelayanan, mengetahui tugas dan tanggung jawabnya, mampu melaksanakan audit sesuai dengan norma auditing. membangun jiwa auditor yang berintegritas dan inpenden. Metode pelaksanaan kegiatan dimulai dengan pemaparan materi dan pendampingan kepada komite audit saat pengawas melakukan audit di kantor pelayanan. Secara umum melalui bimbingan teknik ini komite audit sudah memahami proses audit, ruang lingkup audit, teknik pemeriksaan dan pelaporan audit serta komite memiliki komitmen untuk melaksanakan audit rutin setiap bulan. Dengan meningkatnya kemampuan komite audit, koperasi CU Hati Amboina dapat menghasilkan laporan audit yang dapat digunakan sebagai tolak ukur pencapaian koperasi terhadap kebijakan dan prosedur yang telah ditetapkan.
\end{abstract}

Kata kunci: bimbingan teknis, pengawasan, komite audit

\section{Abstract}

Implementation of supervision or audit is very necessary to ensure healthy cooperative governance. The Audit Committee must understand auditing and audit procedures so that the internal audit activity can run well. The purpose of this activity is to provide technical guidance to the audit committee of the Hati Amboin cooperative credit union to maximize the supervisory function at the service office, know their duties and responsibilities, be able to carry out audits in accordance with auditing norms. build an auditor's spirit of integrity and independence. The method of implementing the activities begins with material presentation and assistance to the audit committee when the supervisor conducts an audit at the service office. In general, through this technical guidance, the audit committee has understood the audit process, audit scope, audit techniques and audit reporting and the committee has a commitment to carry out regular audits every month. With the increasing ability of the audit committee, the CU Hati Amboina cooperative can produce audit reports that can be used as a benchmark for the cooperative's achievement of the established policies and procedures.

Keywords: technical guidance, supervision, audit committee

Copyright (c) 2021 Ignatius Samson Refo, Maria J.F Esomar, Adonia Anita Batkunde

$\triangle$ Corresponding author

Address : Universitas Pattimura

Email : dyahesomar@gmail.com

ISSN 2721- 9224 (Media Cetak)

DOI : https://doi.org/10.31004/abdidas.v2i4.341

ISSN 2721- 9216 (Media Online) 
775 Bimbingan Teknis Pengawasan Bagi Komite Audit Koperasi Credit Union Hati Amboina Ignatius Samson Refo, Maria J.F Esomar, Adonia Anita Batkunde

DOI: https://doi.org/10.31004/abdidas.v2i4.341

\section{PENDAHULUAN}

Pengawasan atau auditing pada koperasi kredit merupakan wujud dari kebutuhan koperasi untuk mengawasi diri sendiri. Pengawasan pada koperasi kredit selain melalukan audit terhadap laporan keuangan dan memperoleh opini, tetapi juga pengawasan dilakukan untuk memberikan saran dan bimbingan sebagai kewajiban untuk melindungi kepentingan anggota. Pengawasan koperasi merupakan pengawasan menyeluruh terhadap tata kelola yang diterapkan koperasi kredit (Lestari \& Kholil, 2018, p. 3).

Dalam melaksanakan tata kelola, koperasi tidak dapat menghidari risiko, baik itu risiko murni dan risiko sprekulatif. Salah satu cara untuk mengurangi risiko yaitu dengan melaskanakan sistim pengawasan yang berkualitas. Pengawasan dilakukan untuk memeriksa, menguji dan mengevaluasi berbagai kegiatan dari koperasi kredit dan untuk menjawab berapa besar manfaat dari kegiatan usaha koperasi dan sejauh mana kegiatan usaha ini mampu meningkatkan kesehjateraan hidup anggota. Auditing koperasi merupakan auditing menyeluruh menyangkut seluruh tata kelola koperasi (Beni \& Manggu, 2019, p. 2).

Pemeriksaan atau auditing dilakukan berdasarkan rangkaian atau langkah yang direncanakan secara teroganisir. Pihak-pihak yang berkepentingan dengan audit koperasi antara lain Anggota yang merupakan pemilik saham dari koperasi, pengurus, pengawas, manajemen dan pemerintah serta lembaga lainnya. Seorang Auditor diharapkan memiliki sikap independensi, tidak memihak dan memiliki pengalaman serta pengetahuan tentang koperasi dan audit. Auditor bertanggung jawab penuh atas pelaksanaan tugasnya, penilaian pendapat dan kesimpulan, membuat rekomendasi atas temuannya dan wajib merahasiakan temuan yang diketahui (Beni \& Manggu, 2019, p. 2).

Koperasi Credit union Hati Amboina merupakan salah satu koperasi yang terbesar di Propinsi Maluku dengan jumlah anggota 5.741 anggota dan tersebar di beberapa kabupaten kota yang ada di Maluku. Koperasi Credit Union Hati Amboina ( CUHA) memiliki kantor induk dan 3 kantor pelayanan. Koperasi Credit Union (CU) Hati Amboina sudah berdiri kurang lebih 13 tahun. Koperasi Credit Union Hati Amboina sebagai sebuah lembaga harus memiliki tata kelola yang baik agar dapat beroperasi untuk melayani anggotanya. Tata kelola Credit Union merupakan kerangka kerja yang mengatur pola kerjasama para pimpinan Credit Union (pengurus, pengawas, manajemen) secara kolektif guna membangun kelembagaan Credit Union yang efektif dan berkelanjutan. Pengurus memiliki tanggung-jawab utama untuk memastikan dilaksanakannya tata kelola 
776 Bimbingan Teknis Pengawasan Bagi Komite Audit Koperasi Credit Union Hati Amboina Ignatius Samson Refo, Maria J.F Esomar, Adonia Anita Batkunde

DOI: https://doi.org/10.31004/abdidas.v2i4.341

Credit Union yang sehat. Manajemen melaksanakan tata kelola sesuai manual operasional yang ditetapkan pengurus yang dijabarkan ke dalam manual prosedur. Pengawas dan komite audit melakukan audit atas aspek kepatuhan, operasional dan keuangan.

Audit dilakukan oleh Pengawas dan dibantu oleh komite audit disetiap kantor Pelayanan Koperasi credit union Hati Amboina. Pengawas dan komite audit diharapkan mampu melaksanakan pengawasan pada aspek kepatuhan, operasional dan keuangan. Sumber permasalahan koperasi Indonesia adalah kompetensi sumber daya tata kelola organisasi yang baik, yang berkaitan dengan praktik keuangan yang jujur dan sehat, akuntabilitas dan transparansi penyelenggaraan. Fungsi pengawasan pada koperasi credit union hati amboina (CUHA) dilaksanakan oleh pengawas yang berkedudukan di kantor induk, melakukan audit per semester, dan komite audit berkedudukan di kantor pelayanan melakukan pemeriksaan rutin setiap bulan, Masalah yang dihadapi dalam pengawasan koperasi credit union hati amboina antara lain regenarasi dan kompetensi komite audit. Untuk meningkatkan komptensi komite audit maka perlu dilakukan bimtek pengawasan sehingga komite audit dapat memiliki keahlian sebagai auditor.
Secara umum kegiatan yang dilaksanakan pada bulan Januari tahun 2020 ini bertujuan untuk memberikan bimbingan teknik pengawasan yang berisikan materi tentang Auditing pada koperasi yang meliputi tiga aspek pemeriksaan yaitu aspek kepatuhan (hukum dan organisasi), aspek operasioanal dan aspek keuangan. Selain sebagai dosen, tim pengabdi juga menjadi pengawas pada koperasi credit union hati amboina (CUHA) dan komite audit berdasarkan struktur organisasi koperasi CU Hati Amboina berada dibawah pengawas. Adapun tujuan khusus dari kegiatan PKM ini antara lain:

1. Memberikan materi dan bimbingan teknis kepada komite audit tentang proses audit di koperasi agar lebih optimal melaksanakan tugas pengawasan.

2. Komite Audit dapat mengetahui tugas dan tanggung jawabnya, mampu melaksanakan audit sesuai dengan norma auditing.

3. Membangun jiwa Auditor yang berintegritas dan inpenden pada komite audit koperasi CU Hati Amboina.

Manfaat Kegiatan pengabdian kepada masyarakat berupa bimbingan teknis tentang pengawasan diharapkan dapat memberikan manfaat bagi peserta yaitu :

1) Adanya transfer knowledge kepada komite audit CU Hati Amboina.

2) Mampu melaksanakan audit kepatuhan, operasional dan keuangan, dengan 
777 Bimbingan Teknis Pengawasan Bagi Komite Audit Koperasi Credit Union Hati Amboina Ignatius Samson Refo, Maria J.F Esomar, Adonia Anita Batkunde

DOI: https://doi.org/10.31004/abdidas.v2i4.341

kemampuan pengetahuan dan keahlian auditing.

\section{METODE}

\section{Tahapan Pelaksanaan Kegiatan}

Metode pelaksanaan kegiatan pelatihan kepemimpinan dengan metode pembelajaran partisipastif, maka disusun kerangka pemecahan masalah pada gambar 1 .

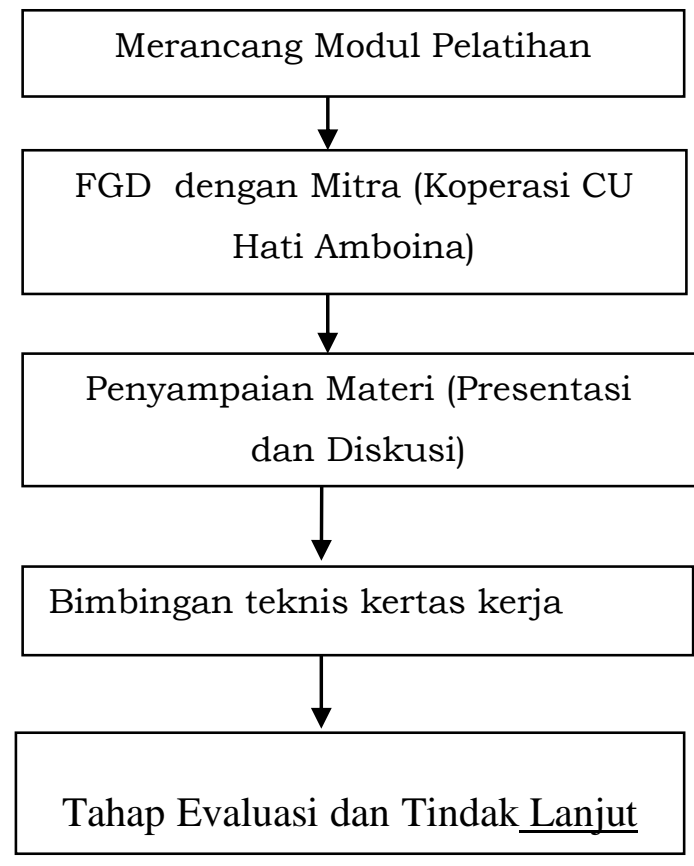

Gambar 1 : Kerangka Pemecahan Masalah

\section{Merancang Modul Pelatihan.}

Tahap pertama yakni menyusun materi pembelajaran yang berisikan ruang lingkup pemeriksaan, teknik pemeriksaan, prosedur pemeriksaan akuntansi keuangan, pemeriksaan aspek kepatuhan (hukum dan organisasi), pemeriksaan aspek operasional dan pemeriksaan aspek keuangan. Kompetensi yang ingin dicapai dari pelatihan ini yaitu meningkatnya kompetensi komite Audit dan mampu mengaplikasikan audit dalam tata kelola Koperasi Credit Union Hati Amboina.

\section{FGD Teknis Pelaksanaan Pengabdian dengan Mitra}

Tahap ini dilakukan untuk mendiskusikan kegiatan pengabdian sebelum dilaksanakan. Mitra pada kegiatan pengadian ini adalah Koperasi Creidit Union Hati Amboina. Metode pelaksanaan program yang dilaksanakan terdiri dari serangkaian proses indentifikasi kebutuhan, sosialsiasi, pelatihan dan penyusunan materi audit. Identifikasi Kebutuhan Mitra bertujuan untuk mengetahui permasalahan mitra. Hal-hal lain yang akan dibahas dalam FGD antara lain terkait pengaturan kembali/penyesuaian jadwal kegiatan.

\section{Pendidikan Dan Pelatihan}

Tahap III yakni Pelatihan yang bertujuan untuk meningkatkan pengetahuan mitra khususnya komite audit koperasi terkait dengan auditing. Pada tahap ini komite audit diberi materi tentang bagaimana melakukan audit berdasarkan aspek kepatuhan (hukumdan organisasi), operasional dan keuangan. Sebelum dilakukan pelatihan, terlebih dahulu diberikan kuisioner pretest yang dilanjutkan dengan 
778 Bimbingan Teknis Pengawasan Bagi Komite Audit Koperasi Credit Union Hati Amboina Ignatius Samson Refo, Maria J.F Esomar, Adonia Anita Batkunde

DOI: https://doi.org/10.31004/abdidas.v2i4.341

pemberian materi pelatihan dan diakhiri dengan posttest untuk mengetahui seberapa besar terjadi peningkatan pengetahuan mitra.

\section{Rencana Aksi}

Pada tahap ini peserta diberi kesemptan untuk mengisi kertas kerja yang didalamnya termuat rencana aksi untuk meningkatkan kemampuan audit.

\section{Tahap Evaluasi dan Tindak Lanjut}

Pada tahap ini, akan dilakukan evaluasi terhadap semua kegiatan yang telah dilakukan dalam kegiatan pengabdian oleh Tim dan juga mitra. Hasil evaluasi menjadi bahan pertimbangan untuk kegiatan pengabdian selanjutnya.

\section{HASIL DAN PEMBAHASAN}

Auditor dalam hal ini komite audit wajib memahami auditing dan prosedur audit agar aktivitas audit pada koperasi Credit Union Hati Amboina dapat berjalan baik, Auditing merupakan evaluasi terhadap suatu organisasi, sistim dan proses. Pelaksanaan audit dilakukan oleh pihak kompeten dan obejktif. Tujuan pelaksanaan audit untuk melakukan verifikasi bahwa subjek dari audit telah diselesaikan atau berjalan sesuai dengan standar dan aturan yang berlaku dalam organisasi.
Auditig koperasi merupakan auditing komprehensif yang menyangkut seluruh tata kelola koperasi. Auditing koperasi tidak hanya berakhir pada laporan audit. Tujuan Audit koperasi memeriksa, menguji, dan mengevaluasi berbagai kegiatan dari koperasi kredit untuk menjawab berapa besar manfaat yang diperoleh anggota melalui berbagai kegiatan usaha dalam bidang hukum, organisasi, operasional dan keuangan. (Wahyudin et al., 2014, p. 4).

Auditor koperasi memberikan pelayanan jasa audit. Auditor harus independen, tidak memihak, menjauhi sikap dan hal - hal yang dapat menggangu atau merugikan kegiatan koperasi, memiliki keahlian, bertanggung jawab dan wajib merahasiakan temuannya.

\section{Ruang Lingkup Pemeriksaan}

Pemeriksaan pada koperasi terdiri dari pemeriksaan atas laporan keuangan, pemeriksaan aspek kepatuhan yang meliputi hukum dan organisasi, pemeriksaan aspek operasional dan pemeriksaan aspek keuangan. Pemeriksaan atas laporan keuangan yaitu mengaudit proses akuntansi dan pelaporan keuangan dari transaksi yang terjadi, bukti penerimaan dan pengeluaran serta pencatatan dan pelaporan. (Lestari \& Kholil, 2018, p. 7).

Pelaporan mengacu pada standar akuntansi SAKETAP (Huvat, 2017, p. 2). Ruang lingkup pemeriksaan menelaah dan 
779 Bimbingan Teknis Pengawasan Bagi Komite Audit Koperasi Credit Union Hati Amboina Ignatius Samson Refo, Maria J.F Esomar, Adonia Anita Batkunde

DOI: https://doi.org/10.31004/abdidas.v2i4.341

menilai kelemahan,memadai tidaknya perangkat pengendalian intern dan mengembangkan pengendalian yang efektif dengan biaya murah. Memastikan ketaatan terhadap kebijakan, rencana dan prosedur yang sudah ditetapkan. Memastikan berapa jauh aset/harta organisasi dipertangungjawabkan dan dilindungi dari kemungkinan terjadinya segala bentuk pencurian, kecurangan dan penyalahgunaan.

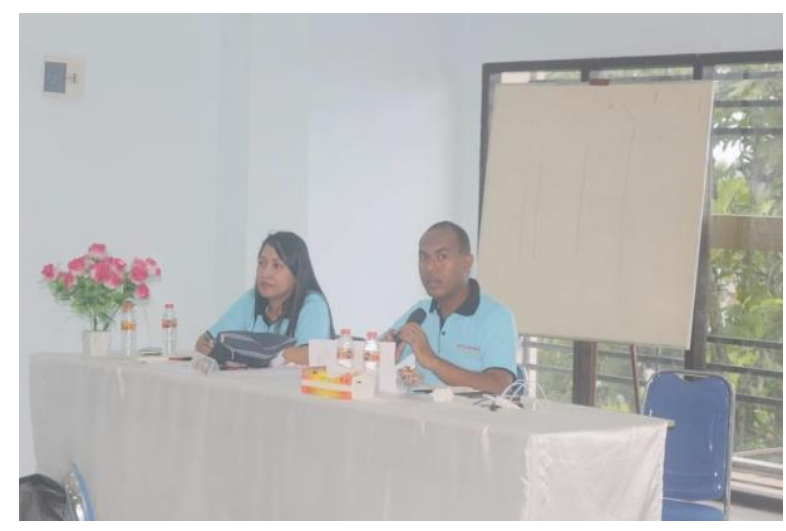

Gambar 1. Pembahasan materi

Sesi berikut tentang teknik pemeriksaan Teknik pemeriksaan merupakan cara yang diterapkan dalam pemeriksaan untuk memperoleh bukti yang cukup kuat dan kompeten. Teknik pemeriksaan dengan melakukan tanya jawab, pengamatan, inspeksi, pemeriksaan dan perhitungan fisik kas, pencocokan, pemeriksaan dokumen, pengujian dan penelusuran prosedur pembukuan, analisa perkiraan perhitungan, perbandingan, konfirmasi dan penelaah atas catatan non keuangan, teknik pemeriksaan tanya jawab dilakukan dengan cara mengaujukan pertanyaan - pertanyaan kepada manajemen dan stakeholder yang lain. Pengamatan merupakan teknik melihat secara cermat dan mencatat hal-hal yang penting dari suatu prosedur untuk mengamati cara-cara penerapan, dan efektivitas penerapan serta kecermatan dan kehati-hatian para manajemen melaksanakan aktivitas pekerjaannya, menguji catatan, dokumen dan atas harta tetap, mencocokan dokumen. Teknik pemeriksaan lainnya penelaah analitis dan catatan non keuangan penelaahan analitis membandingkan angka - angka dan pergerakan perubahan yang tidak biasa, penelaahan atas catatan non keuangan yaitu membaca, mencatat dan menyalin catatan - catatan seperti AD/ ART, notulen atau surat keputusan, menelaah rencana dan kebijakan koperasi kredit, dan memastikan semua transaksi telah disahkan dan dicatat, dibukukan sebagaimana mestinya. Audit atas akta pendirian anggaran rumah tangga bertujuan menilai apakah koperasi $\mathrm{CU}$ Hati Amboina dan setiap kantor pelayanan yang diaudit memiliki badan hukun, dan memiliki izin pendirian, akta pendirian, anggaran dasar dan anggaran rumah tangga. Pada Aspek Hukun juga diperiksa soal ketaatan lembaga membayar pajak. Audit atas organisasi merupakan audit atas sistim yang diterapkan dalam organisasi koperasi, Audit 
780 Bimbingan Teknis Pengawasan Bagi Komite Audit Koperasi Credit Union Hati Amboina Ignatius Samson Refo, Maria J.F Esomar, Adonia Anita Batkunde

DOI: https://doi.org/10.31004/abdidas.v2i4.341

pada aspek ini menilai kebijakan, dan seluruh perangkat Audit.

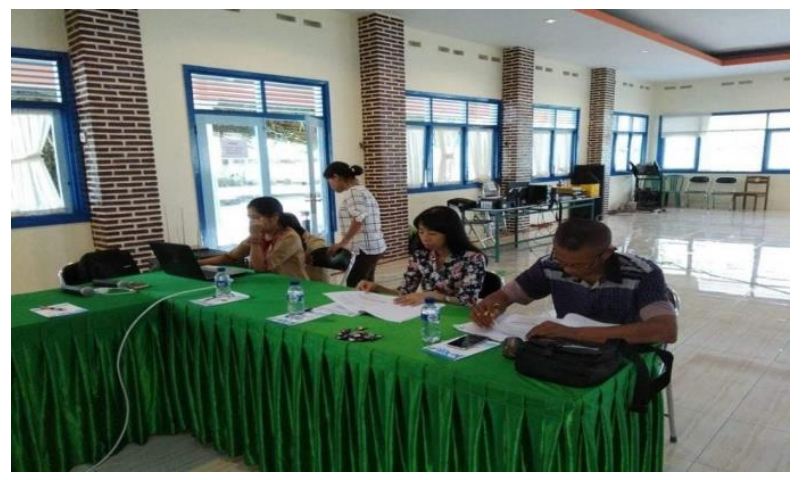

Gambar 2. Pelatihan mengisi kertas kerja.

Audit pada aspek operasioanl mencakup audit atas pengendalian internal dan atas akuntansi keuangan. Pada aspek ini akan diperiksa apakah pencatatan sesuai dengan kebijakan yang berlaku dan apakah sesuai dengan bukti keuangan. (Reti, 2019, p. 2). Audit pada aspek keuangan mencakup audit atas aset, atas kewajiban dan ekuitas, pendapatan, beban dan perhitungan pajak. Untuk memperoleh temuan, menyusun kesimpulan dan saran maka komite audit harus menemukan sumber masalah dengan memperoleh bukti-bukti pemeriksaan yang kompeten melalui prosedur pemeriksaan. Kecukupan bukti dapat dilihat dari jumlah bukti yang diperoleh. Bukti pemeriksaan yang kompeten berhubungan dengan keakuratan dan relevansi dari bukti-bukti yang didapatkan.
Dengan terlaksananya bimtek pengawasan diharapakan dapat melahirkan komite audit yang handal, yang mampu melakukan pemeriksaaan dan menyusun laporan audit yang jelas dan lengkap. Penyampaian laporan audit berisikan hasil temuan, penilaian, pendapat, kesimpulan serta saran tindak lanjut.

Pengawasan pada koperasi sangat penting dilaksanakan., pengawasan dilakukan untuk menghindari kecurangan dan merupakan pengendalian internal koperasi. Pelaksaanaan audit dapat meningkatkan kinerja koperasi demi terciptanya kredibilitas yang lebih dari masyarakat (TYAS, n.d., p. 2).

Hasil pengawasan akan membuktikan apakah laporan keuangan yang merupakan suatu laporan pertanggungjawaban menggambarkan posisi keuangan dan prestasi pencapaian usaha koperasi dikelola secara baik atau tidak. Kegiatan audit yang dilaksanakan pada koperasi CU Hati Amboina di kantor pelayanan dilakukan oleh komite audit yang mana komite audit wajib memiliki kemampuan audit, karena pemeriksaan menggunakan ketelitian dan keahlian. Keahlian dari komite audit akan membantu pengawas koperasi untuk menilai tanda-tanda penyimpangan yang terjadi, sehingga pengawasan pada koperasi credit union Hati Amboina di setiap kantor pelayanan dapat berjalan dengan baik. 
781 Bimbingan Teknis Pengawasan Bagi Komite Audit Koperasi Credit Union Hati Amboina Ignatius Samson Refo, Maria J.F Esomar, Adonia Anita Batkunde

DOI: https://doi.org/10.31004/abdidas.v2i4.341

\section{Rencana Aksi}

Setelah mengikuti bimbingan teknik pengawasan, komite audit diberikan instrument kertas kerja audit. Kerta kerja audit merupakan kertas kerja yang merupakan intrumen audit yang dikeluarkan divisi pendidikan dan pelatihan pusat koperasi credit union BKCU Kalimantan. Kertas kerja audit merupakan instrumen pemeriksaan yang berisikan instrumen audit dari aspek kepatuhan, operasional dan keuangan.

Komite audit membuat rencana tindak lanjut atas program kerja pengawasan koperasi CU Hati Amboina. Program kerja tersebut merupakan program kerja audit rutin yang dilaksanakan setiap bulan. Komite audit yang sudah mengikuti bimbingan teknis diharapkan dapat menjadi pemateri pada kegiatankegiatan berikutnya.

\section{SIMPULAN}

Berdasarkan hasil kegiatan pelatihan, dan pembahasan yang telah disampaikan, maka dapat dibuat kesimpulan sebagai berikut:

1. Komite audit dapat memahami tugas dan tanggung jawabnya, memahami proses audit yang meliputi audit aspek keuangan dan operasional.

2. Pengawasan di setiap kantor pelayanan koperasi CU Hati Amboina dapat dijalankan sehingga pengurus koperasi, staf dan anggota dapat memperoleh manfaat dari pengawasan yang dilaksanakan.

3. Program pengabdian ini berjalan dengan baik dan adanya komitmen bersama untuk melaksanakan fungsi pengawasan di Koperasi Credit Union Hati Amboina secara konsisten dan berkelanjutan untuk menghasilkan tata kelola organisasi yang baik.

\section{UCAPAN TERIMA KASIH}

Kegiatan ini dapat berjalan dengan baik karena dukungan berbagai pihak, oleh karena itu tim menyampaikan ucapan terimakasih kepada Fakultas Ekonomi Universitas Pattimura dan STPAK yang telah mendukung kegiatan ini. Kepada Pihak BKCU Kalimantan dan Koperasi Credit Union Hati Amboina yang sudah menjadi mitra dalam kegiatan Pengabdian masyarakat dan kepada pihak penerbit jurnal yang bersedia menerima artikel ini untuk dipublish.

\section{DAFTAR PUSTAKA}

Beni, S., \& Manggu, B. (2019). Bimbingan teknis pengawasan koperasi se-kabupaten Bengkayang tahun 2019: Manajemen pengawasan koperasi. PengabdianMu: Jurnal Ilmiah Pengabdian Kepada Masyarakat, 5(1), 67-71.

Huvat, Y. J. (2017). Analisis Penerapan Standar Akuntansi Keuangan Entitas Tanpa Akuntabilitas Publik (SAK-ETAP) pada Koperasi CU (Credit Union) Daya Lestari di Samarinda. Ekonomia, 6(1), 9- 
782 Bimbingan Teknis Pengawasan Bagi Komite Audit Koperasi Credit Union Hati Amboina Ignatius Samson Refo, Maria J.F Esomar, Adonia Anita Batkunde

DOI: https://doi.org/10.31004/abdidas.v2i4.341

23.

Lestari, F. D., \& Kholil, M. (2018). Efektifitas Pembinaan dan Pengawasan Koperasi Oleh Pemerintah Daerah (Studi di Dinas Perdagangan, Tenaga Kerja, Koperasi dan Usaha Kecil Menengah Kabupaten Karanganyar). Jurnal Privat Law, 6(1), 46-59.

Reti, D. (2019). Peranan Internal Audit Dalam Pengawasan Piutang Usaha Pada CU Daya Lestari Kabupaten Kutai Barat. OBOR: Oikonomia Borneo, 1(1), 98-104.

TYAS, V. P. (n.d.). POLA PENJAMINAN RESIKO PIUTANG ANGGOTA OLEH PUSKOPDIT BKCU KALIMANTAN. Jurnal Hukum Prodi Ilmu Hukum Fakultas Hukum Untan (Jurnal Mahasiswa S1 Fakultas Hukum) Universitas Tanjungpura, 1(2).

Wahyudin, A., Cahyaningdyah, D., \& Baroroh, N. (2014). Penguatan Sistem Pengendalian Intern (Spi) Sebagai Upaya Meminimalisir Praktek Tidak Sehat Dalam Tata Kelola Keuangan Koperasi. Rekayasa: Jurnal Penerapan Teknologi Dan Pembelajaran, 12(2), 132-140. 